\title{
Development Program of Chemical Industry Based Computer Assisted Instruction for Students of Industrial Engineering Department in Indonesia
}

\author{
Leola Dewiyani' ${ }^{1}$ Anwar Ilmar Ramadhan ${ }^{2}$, Ery Diniardi² \\ ${ }^{1}$ Industrial Engineering Department, Faculty of Engineering, Universitas Muhammadiyah Jakarta, Jakarta, \\ Indonesia \\ ${ }^{2}$ Mechanical Engineering Department, Faculty of Engineering, Universitas Muhammadiyah Jakarta, Jakarta, \\ Indonesia \\ Email: *anwar.ilmar@umj.ac.id
}

Received 21 April 2016; accepted 6 June 2016; published 9 June 2016

Copyright (C) 2016 by authors and Scientific Research Publishing Inc.

This work is licensed under the Creative Commons Attribution International License (CC BY). http://creativecommons.org/licenses/by/4.0/

(c) (i) Open Access

\section{Abstract}

This study aims to improve the competence of students of the Department of Industrial Engineering in Indonesia in the subject of Chemical Industry, in particular through the model-based teaching materials CAI (Computer Assisted Instruction) in the form of an interactive CD. In particular, the study was carried out for the purposes of: 1) designing and developing models of devices based learning CAI (Computer Assisted Instruction) systematically in prototype form, 2) producing an interactive $C D$ as a model learning devices Chemical Industry based CAI (Computer Assisted Instruction) to improve the competence of students of the Department of Industrial Engineering in Industrial chemistry courses. The benefits of this research are: 1 ) for the government, the results of this study can be used as a reference in implementing educational policies, especially to enhance the nation's competitiveness in the era of informatics; and 2) for the Department of Industrial Engineering in Indonesia, the results of this research can be used to enhance learning that can improve the competence of students in the subject of Chemical Industry, which in turn can be passed with high achievement. Products produced in the first year are a design-based teaching materials CAI (Computer Assisted Instruction) in prototype form, with the following steps: 1) preproduction which includes needs analysis, identifying and analyzing the needs based on the content of curriculum and learning model based CAI (Computer Assisted Instruction), the development of a concept related to Chemical Industry, the development of multimedia content that includes developing materials, animation, and evaluation related to industrial chemicals, gathering material to make the recording sound, shooting, and editing with regard to the development of

\footnotetext{
*Corresponding author.
} 
teaching materials chemical Industry based CAI (Computer Assisted Instruction), as well as developing the storyboard as the layout of the multimedia contents by involving experts multimedia; 2) production process that includes design/design and conduct of programming a prototype which means at this stage of the design and development of teaching materials based CAI (Computer Assisted Instruction); and 3) post-production which includes the evaluation justification experts, conducted trials on stakeholders, being revised based on input from experts, and doing packing and labeling.

\section{Keywords}

Development, Competence, Industry, CAI, Chemical

\section{Introduction}

Computer is one medium that can help students in drill and practice activities. With the support of software in the form of programs, students can train themselves to use it properly, develop, and produce works in accordance with the capabilities, expertise, and needs. One program that can help a student is CAI. CAI (Computer Assisted Instruction) is made by creative people who create a medium of learning with learning strategies that are based on student needs, where students can obtain information/messages in a fun and personalized, because CAI provides a method of learning in the form of tutorials, drill and practice, simulations, problem solving, data base up to the games.

CAI (Computer Assisted Instruction) or CAL (Computer Assisted Learning) is defined as computer assisted learning (PBK). CAI but the term is more familiar, so henceforth the term CAI is used. There are many definitions kicking CAI or Computer Assisted Instruction. Among them is the general definition expressed by Hannafin, namely that "CAI regards to any learning situation in which the activities and learning materials delivered via computer” [1]. CAI also combines and synergizes all media consisting of text, graphics, images, video, animation, music, narration and interactivity that are programmed based on the theory of learning. An opinion about CAI, which is an interactive application program that can be used as a medium, conveys information as well as evaluation of learning media. Furthermore CAI can be used as a tool in independent learning for students. Use of CAI in learning is one of the alternative methods that attract and are able to provide a real picture of the material that is abstract [2].

The term generally refers to all the CAI education softwares that are accessed through a computer where the user can interact with it. The computer system can present a series of learning programs to students, either in the form of information concept and practice questions to achieve certain goals, or in the student learning activities by interacting with the computer system. While in his position it can be said that CAI is the use of computers as an integral part of the instructional system, where the user is usually tied to the two-way interaction with the computer. CAI is interpreted as forms of learning that puts computers in the role of educator [3]-[5]. Meanwhile, CAI is a learning program that is created in the computer system, which conveys a pre-defined material directly to the user [6]-[8]. The subject matter already programmed can be served simultaneously between the components of the image, text, color and sound.

Activities to do with CAI include 4 main categories, namely: 1) Drill and Practice, 2) Tutorial, 3) Games, and 4) Simulation. In training activities, the computer gives questions about a topic fatherly solved by the students and the computer gives feedback based on the student's response. Activity tutorial intends to teach new information on a topic. The game can serve as a presenter or a new lesson material as well as the reinforcement of the lessons learned through the activities of other students. In the simulation or modeling, computer simulations or models provide a concept or event to be input by the student and the computer will give a response to these inputs as the actual system will act. So CAI is learning everything that is programmed using a computer and allows the user to interact with and usually for the purpose of independent learning.

One factor determining the quality of graduates majoring in industrial engineering is the quality of the implementation of learning. Besides, the main obstacle has been the lack of teaching materials based CAI (Computer Assisted Instruction). In fact, the competence of students of the Department of Industrial Engineering in 
Industrial Chemistry course is still very low. Therefore we need an innovative teaching materials based CAI (Computer Assisted Instruction) in the form of an interactive CD that does not exist in the Department of Industrial Engineering in Indonesia to improve the competence of students in the subject of Chemical Industry. Thus, by using this interactive CD, students of Department of Industrial Engineering in Indonesia can increase their competence in the Industrial Chemistry Lecture.

\section{Research Method}

This study uses the procedures of research and development (Research and Development) is thus through the procedures and field trials. The method of research and development in principle is a process for the development of a product of education and next validated [8]-[10]. The products that will be developed and validated teaching materials Chemical Industries is based CAI (Computer Assisted Instruction). In this study testing the effectiveness, efficiency and attractiveness of teaching materials based Industrial Chemistry CAI (Computer Assisted Instruction), researchers used an assessor or observation and feedback of students, peers, and student learning outcomes. The effectiveness of the tested models of student learning outcomes by using pre-test and post-test, while the appeal is usually measured by the scale of attitudes, self-evaluation and student opinion regarding the teaching material based Industrial Chemistry CAI (Computer Assisted Instruction) in accordance with the conditions and needs.

The sampling technique used is sampling considerations (purposive sampling) which have the characteristics in classes where many students have to follow a remedial program for the course Chemical Industry. To collect data on the initial information about the student learning process Chemical Industries today as a needs analysis study represented 10 students to a preliminary study. Similarly, the early stages of field tests, the study only do one class which classes are being/well with the base average GPA is determined 3. Based on these considerations such as class field testing of teaching materials based Industrial Chemistry CAI (Computer Assisted Instruction). Planning research steps at the stage of the seventh due to the lack of researchers and according to the needs of the research itself as well as by statements Borg and Gall, development of teaching materials is a form of research and development of small-scale limited [11]-[14]. This means allowed if it gets on the seventh stage, but does not detract from the purpose to be achieved that is obtained in the form of educational products based teaching materials Chemical Industries CAI (Computer Assisted Instruction). Step-by-step development of small-scale research through three main steps: pre-development, development models and application models, as for the chart as follows (Figure 1):

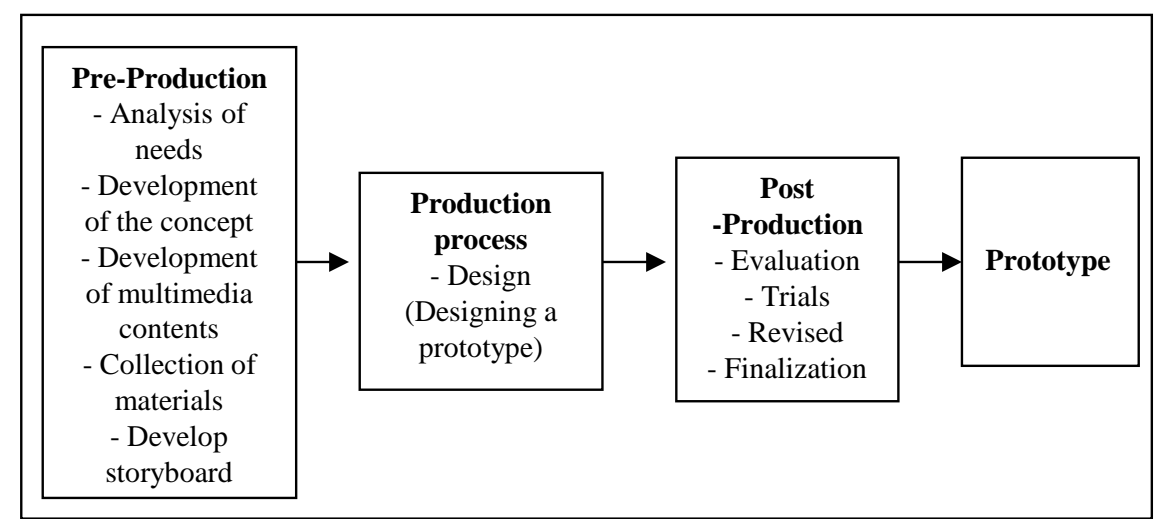

Figure 1. Flow chart of this research [15].

For data-collection efforts necessary research then developed the instrument in accordance with the needs of the data and information collected. The study consists of a grating and instrument in the form of questionnaires and tests. The data analysis technique consists of quantitative and qualitative. Quantitatively analyzed using quantitative descriptive statistics inferential analysis, while quantitative analysis with a way to describe in a narrative. Qualitative data analysis procedure performed through three stages, namely the process of data reduction, data presentation, and decision making. The resulting product is design-based teaching materials CAI (Computer Assisted Instruction) in prototype form, with the following steps: 


\subsection{Pre-Production}

1) Analysis of needs: identify and analyze the content based on the needs of the curriculum and the learning model based CAI (Computer Assisted Instruction). The survey research was conducted by using descriptive analysis of quantitative and qualitative.

2) Development of the concept: to develop concepts related to Industrial Chemicals.

3) Development of multimedia contents: developing materials, animation, and evaluation related to Chemical Industry.

4) The collection of materials: voice recording, shooting, and editing teaching materials related to the development of Chemical Industry based CAI (Computer Assisted Instruction).

5) Develop storyboard as the layout of the multimedia contents involving multimedia expert.

\subsection{Production Process}

Design: design/design and prototype programming pass. At this stage, do the design and development of teaching materials based CAI (Computer Assisted Instruction). Research in this phase is the research and development (developmental research) with reference to some theoretical studies on the development of the learning procedure is standard and the identification and analysis of the learning content.

\subsection{Post-Production}

1) Evaluation: do justification expert.

2) Tests: tests on stakeholder.

3) Revisions: revisions based on feedback from the experts.

4) Finalization: do packing and labeling.

\section{Result and Discussion}

\subsection{Production Description}

Before the product is produced teaching materials produced in the research development of this form of Compact Disk (CD) Study of Chemical Industry of interactive, first performed the development of concepts related to the Chemical Industry. Then do the development of the Compact Disk (CD) Chemical Industries interactive learning means that these materials are two-way interaction. Users can choose to learn the material on the CD as desired. This instructional material created using Adobe Flash CS6 program adobe products. Making interactive $\mathrm{CD}$ instructional materials is done with three stages in accordance with the draft design plan, namely pre- production, production, post-production.

Pre-production stage is the initial stage in the form of a needs analysis, development of teaching materials, the content development of interactive CD, the collection of support materials, and the development of design in the form of story board. The results of a needs analysis based on empirical studies of the students and teachers that need their innovative teaching materials from the chemical industry. Because the chemistry industry is a lesson that is still considered difficult and teaching materials available still conventional so less attractive to be studied. Material development conducted by researchers with justified by two experts in the field of chemical industry. The material developed in this teaching material such as 7 chapters, namely: chapter 1 of a chemical messenger industry, chapter 2 of stoichiometric, chapter 3 of the solution, the 4th chapter of the chemical balance, chapter 5 of aliphatic hydrocarbons, chapter 6 cyclic compounds and aromatic, and chapter 7 of the chemical industry.

The collection of material support in making this interactive CD is sound, graphics, music, animation which is the source at the design stage. Graphing through the process of cut and paste and editing using Adobe Photoshop CS6 program adobe production. Making good sound or music recording and editing using the program adobe audition adobe production. Making animation using Adobe Flash program from Adobe CS6 production. Designing the contents of interactive or multimedia CD was developed to create a story of board. Storyboarded the entire lay out of the contents of this interactive with CD. Production stage is the process of making of interactive CD. This stage is the post production of the overall interactive CD's. All material is good material, graphics, animation and sound or music designed by researchers correspond story of board planned. The program used in the production stage is adobe flash CS6 production of adobe. 
Post-production stage is the stage of validation in making this interactive CD. The validation phase is intended to look at the weaknesses and shortcomings of this interactive CD. The results of this phase in the form of recommendations for the revision of the product. Phase validation is performed to the user with technical experts and one to one and small group. Interactive $\mathrm{CD}$ that has become temporarily given to students and experts either an individual or a limited group to try this interactive CD. Next they were asked or fill out a questionnaire to provide feedback according to what they feel. The result of the material used as input to revise the interactive CD. CD which has undergone further improvements on finalization and labeling and packaging as a prototype. Prototype interactive CD further as materials for post hock production and dissemination in the form of a field test which is the advanced research.

\subsection{Products Characteristics}

Teaching materials in the form of interactive compact disc containing the software program or on the chemical industry. This CD is a combination of media text, audio and visual, interactive or multimedia called. The contents of this interactive CD consist of four parts: the intro, the main menu, materials, training and evaluation (Figure 2). Intro menu contains appetizers frame when the first time the program is opened. Furthermore, this intro into the first gate to enter the main menu. In this intro available navigation keys "enter" whose functions go to the main menu:

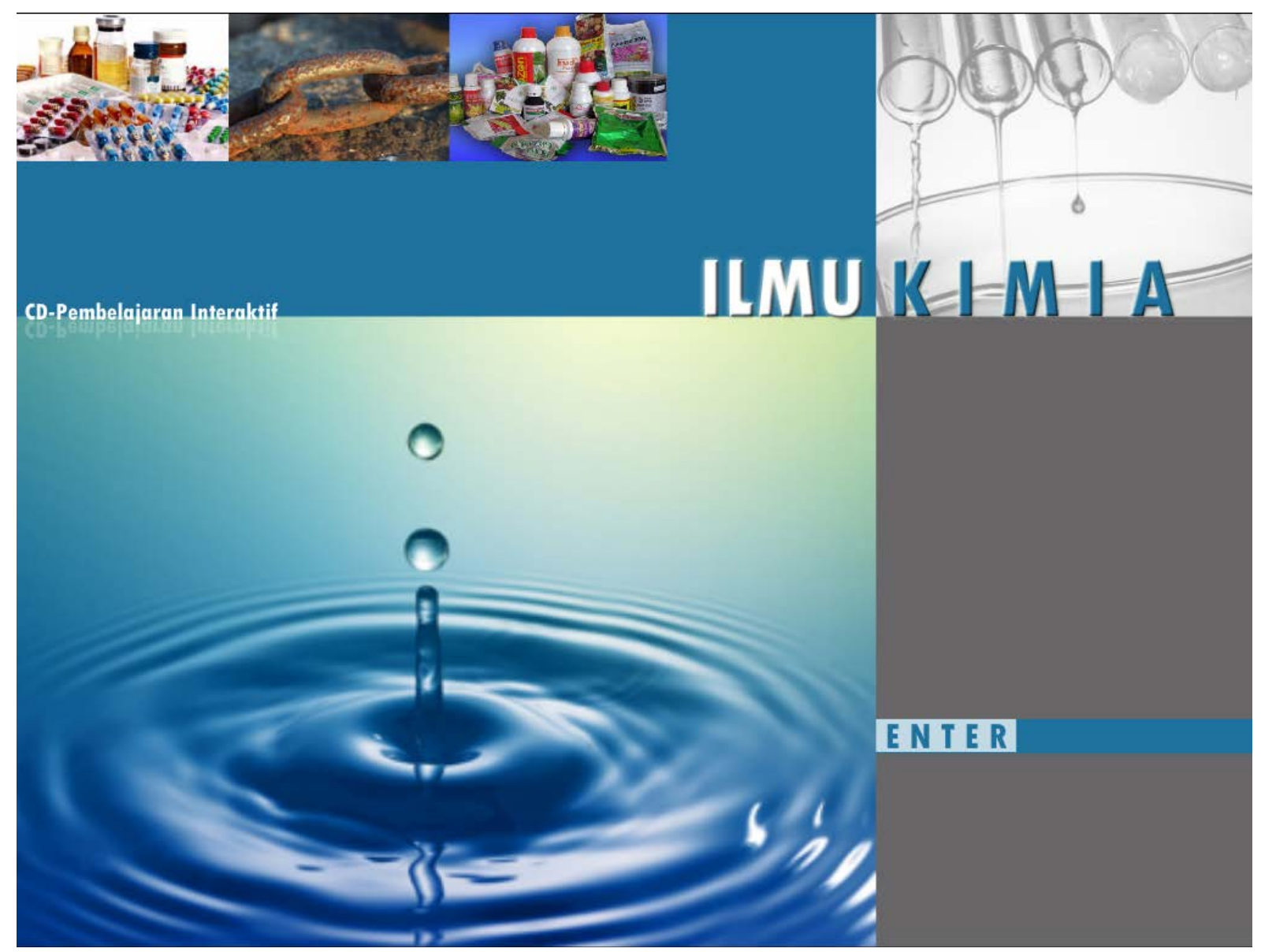

Figure 2. Frame of introduction [15].

Frame main menu contains interface frame that can go the whole material content of this interactive CD. On the main menu navigation buttons are separately enter the whole chapter CD material is composed of seven chapters (Figure 3). 


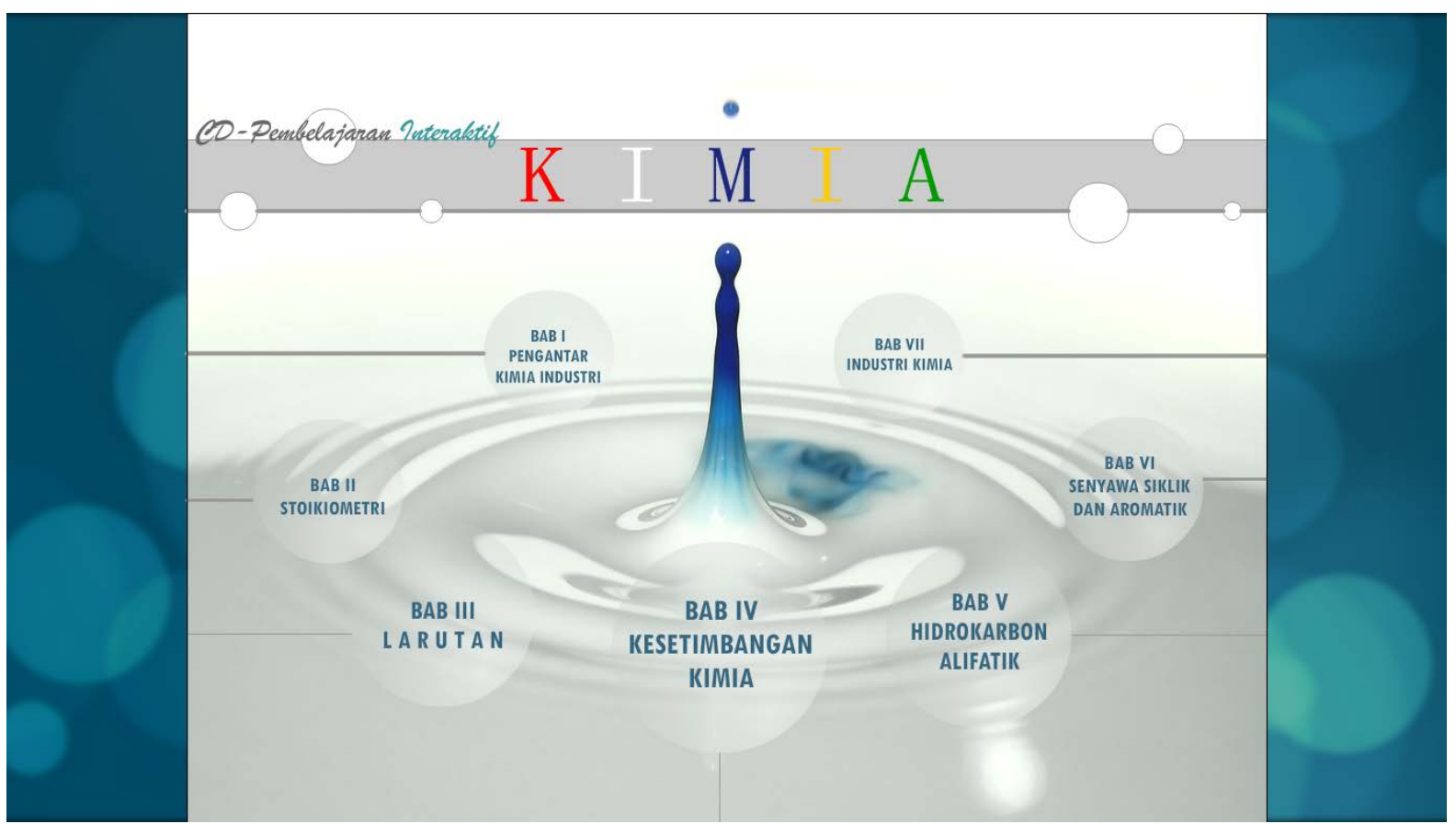

Figure 3. Frame of main menu [15].

Furthermore, each of the navigation key to enter the frame material of each chapter. In every frame material contained navigation buttons "next" and "prev". Navigation key "next" function is continued in the form of the material in the chapter or sub-chapter discussion of subjects such material. Navigation key "prev" to go back to the previous section, and so on. In the chapter and sub-chapter menus are navigation buttons material, training, evaluation, exit, intro (Figure 4). Navigation functions material to the main menu that contains a menu interface to all content of the material, exercise its functions for the navigation key to enter the exercise menu containing practice questions in the beb. Navgasi button to enter the frame evaluation function evaluation is the final part of the learning interactive in CD.

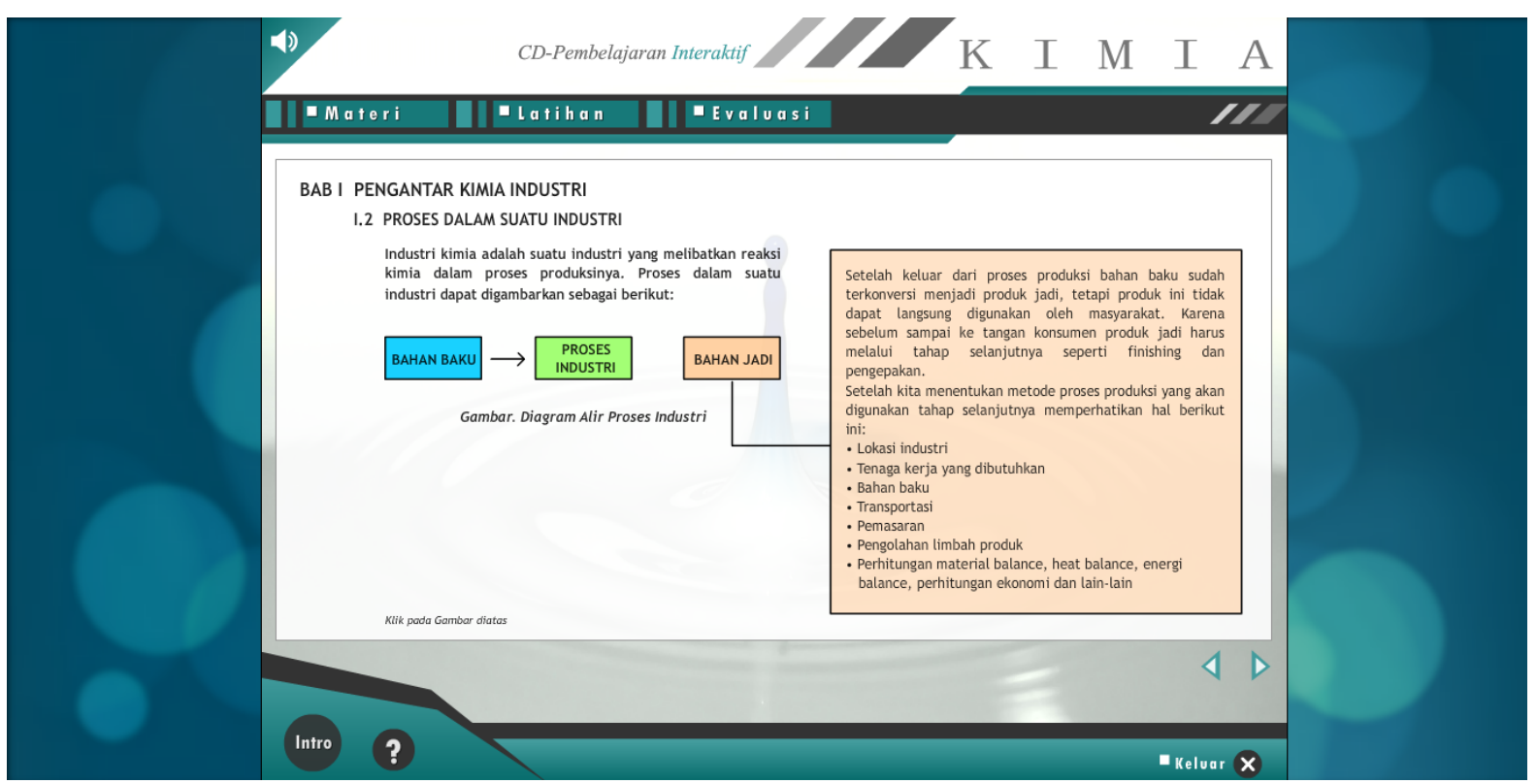

Figure 4. Frame of section menu [15]. 
The menu contains practice exercises to determine the extent to which users understand the content of the material each chapter of this interactive CD. Exercises include answer key as answer key. If the answer button on tap will be out the answer key (Figure 5).

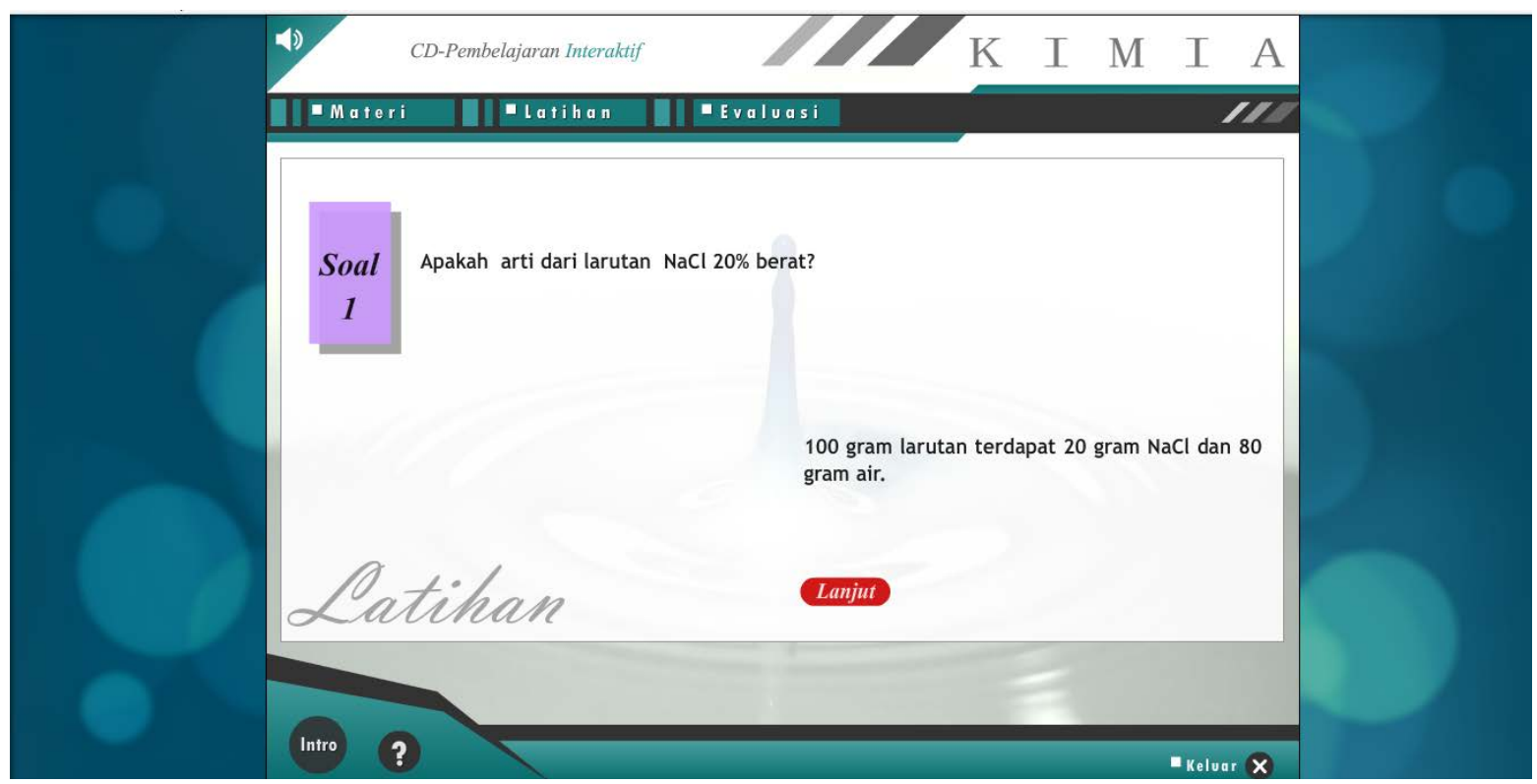

Figure 5. Frame of exercise menu [15].

Menu evaluation to evaluate the extent to which the user's understanding of the material throughout the chapters in the CD. The questions in the evaluation of multiple-choice questions and so provided an alternative answer. The users simply press the answer option (Figure 6).

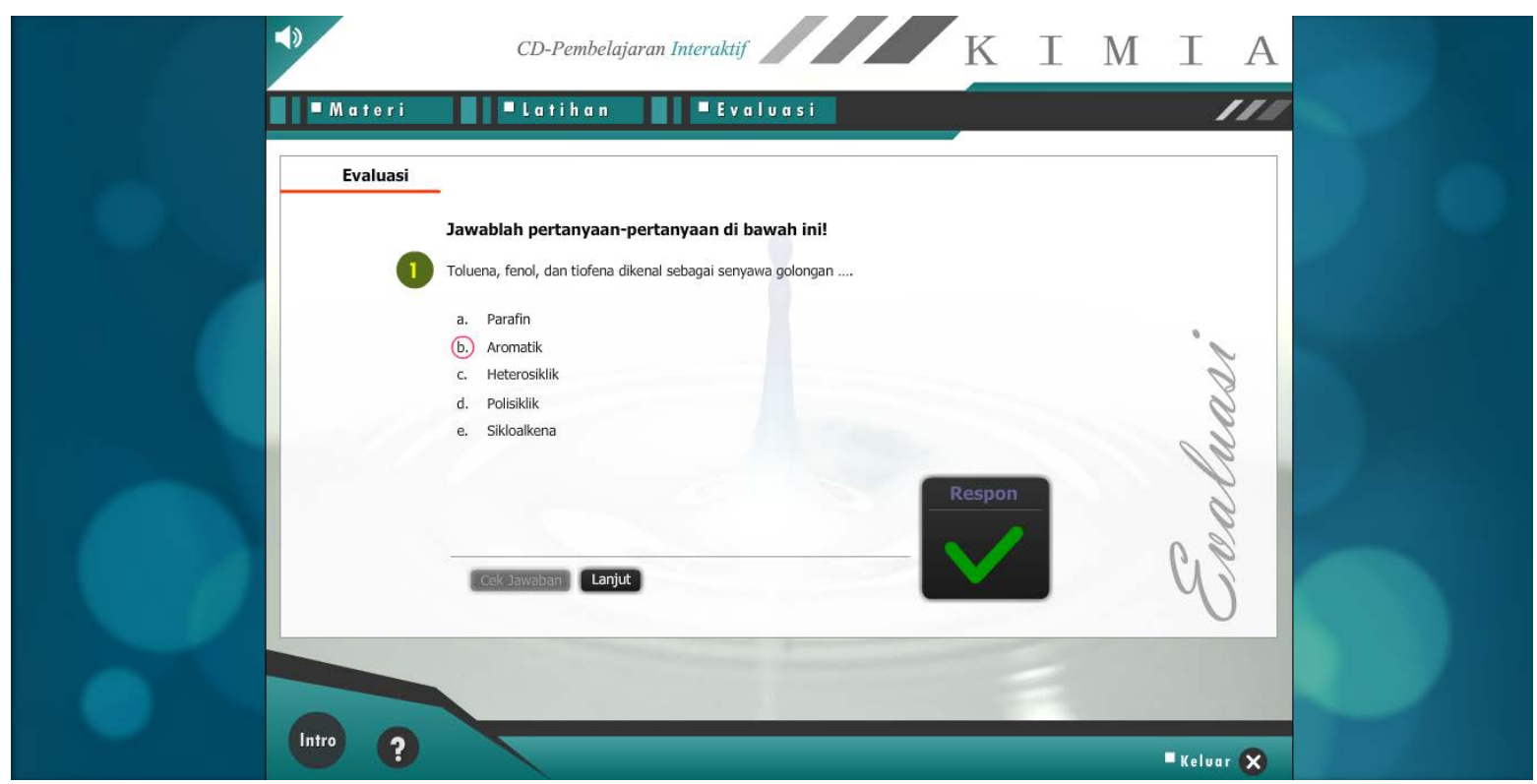

Figure 6. Frame of evaluation menu [15].

In the evaluation menu also provided the answer function checks to see answers are correct or not. Having completed work on all evaluation questions then the end will show the value and number of answers about who is right or wrong. Furthermore, can hit the back button to repeat the evaluation (Figure 7). 


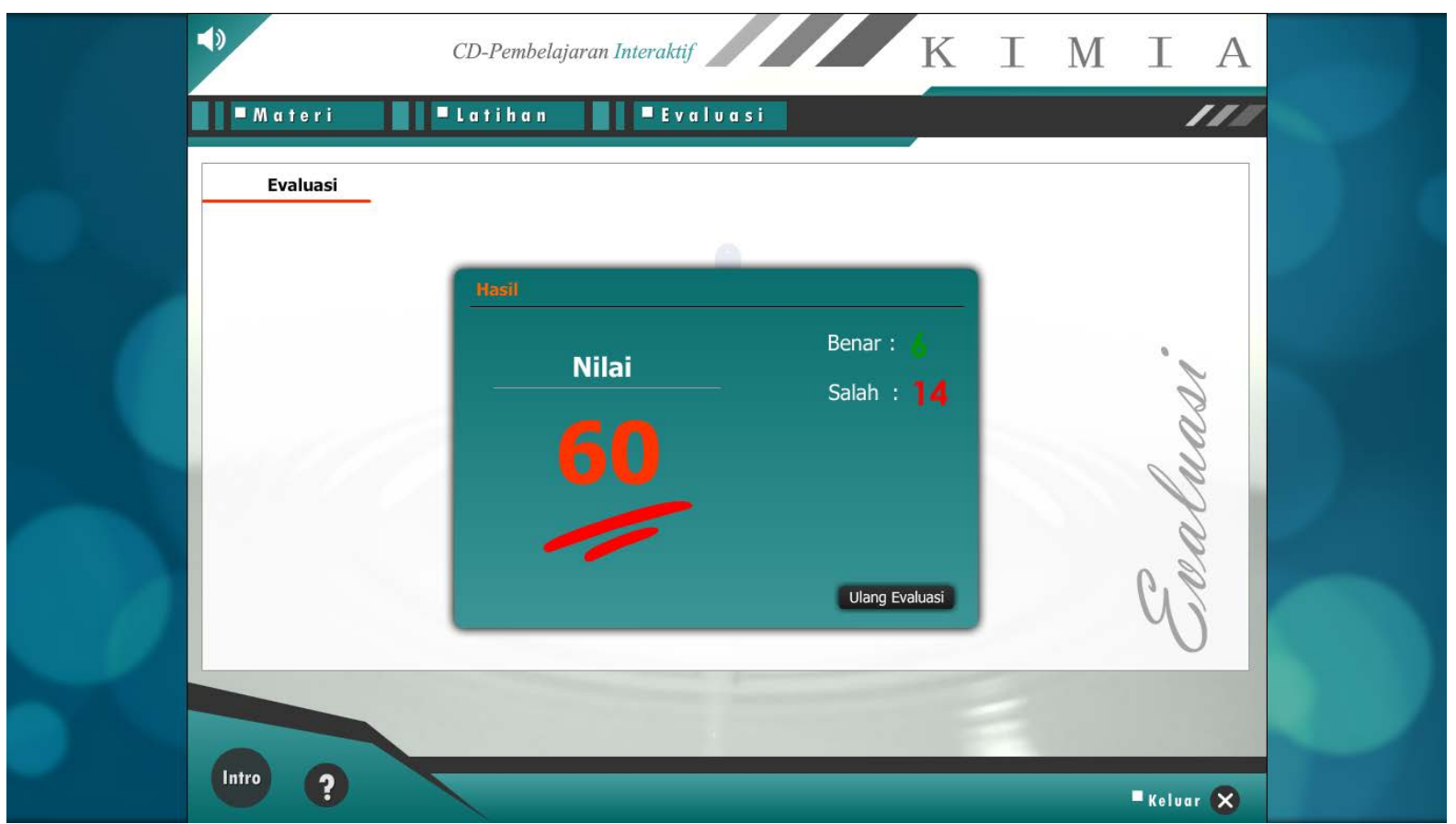

Figure 7. Frame of final score [15].

\section{Advantages Program}

Some of the advantages of the program of teaching materials based CAI of Chemical Industry are as follows:

1) Capacity program file-based teaching materials Chemical Industries of CAI approximately $30 \mathrm{MB}$ small enough so as not to burden the load computer system.

2) Industrial Chemistry program instructional materials based CAI is interactive as the user desires.

3) The navigation buttons at the Industrial Chemistry program instructional materials based CAI is quite simple so familiar to end users (end-user).

Programs can be conducted themselves independently. Learning program can be customized by the end user learning speed.

\section{Procedures Utilization Products}

The program has been equipped with the system start up autorun CD program will automatically run once inserted into the CD-ROM drive. Applications used files have. exe format that does not require other supporting software to display the contents of the CD program. After running the program it will perform for the first time intro and title of the program. Then the program will go automatically to the main menu contains menus on the $\mathrm{CD}$ of this program is the material and evaluation.

\section{Product Limitations}

In product development of teaching materials based Industrial Chemistry with CAI (Computer Aided Instruction) has been carried out development measures in accordance with predetermined procedures, namely the requirement analysis phase, design phase or the design, development and implementation, as well as the evaluation phase. However, with the limited time that I owned developer, the development of concepts related to teaching materials Chemical Industry is still limited and not comprehensive for all concepts Industrial Chemicals such that it needs to be developed again.

\section{Conclusions}

The results of this study provide the following conclusions:

1) Based on the description of the product development procedure of teaching materials based Industrial Chemistry CAI (Computer Aided Instruction), it can be concluded that the product development program based teaching materials of Chemical Industries CAI (Computer Aided Instruction) are interactive learning Industrial Chemistry. 
2) The results of product development of teaching materials based Industrial Chemistry CAI (Computer Aided Instruction) have implications associated with the development of computer assisted learning programs to help students in the learning of Chemical Industry. Hopefully this program will have a positive impact on the quality of students understanding in learning Industrial Chemistry and graduated with high achievement.

\section{References}

[1] Hannafin, M.J. and Peck, K.L. (1988) The Design Development and Evaluation of Instructional Software. Macmillan. Publishing Company, New York.

[2] Elida, T. and dan Nugroho, W. (2003) Pengembangan Computer Assisted Instruction pada Praktikum Mata Kuliah Jaringan Komputer. Seminar Nasional Teknologi Pendidikan Yogyakarta. Jurusan Teknologi Pendidikan. Universitas Negeri Jakarta.

[3] Rigney, J.W. (1978) Learning Strategies: A Theoretical Perspective. Academic Press, New York.

[4] Thompson, J.F. (1975) Foundation for Vocational Education: Social and Philosophical Concept. Prentice-Hall, Inc., New Jersey.

[5] Krisnadi, E. (2000) Pemanfaatan Program CAI sebagai Sarana untuk Membantu Peserta Didik dalam Menyerap Konsep-Konsep Matematika dengan Pendekatan Abstrak-Konkret-Abstrak.

[6] Bruner, J.S. (1966) Toward a Theory of Instruction. Norton, New York.

[7] Merril, P.F. (1996) Computers in Education. Allyn \& Bacon, USA.

[8] Brog, W.R. and Gall, M.D. (1979) Educational Research: An Introduction. David McKay Company, New York.

[9] Dansereau, D.F. (1985) Learning Strategy Research. Volume 1, Lawrence Erlbaum Associates, Hillsdale, $209-239$.

[10] Gagne, R.M. (1985) The Conditions of Learning. Holt, Rinehart and Winston, New York.

[11] Geisert, P.G. (1995) Computers and Curriculum. Allyn \& Bacon, USA.

[12] Kintsch, W. (1970) Learning Memory, and Conceptual Processes. Weley, New York.

[13] Mayer, R.E. (1977) The Sequencing of Instruction and the Concept of Assimilation-to-Schema. Instructional Science, 6, 369-388. http://dx.doi.org/10.1007/BF00121548

[14] Reigeluth, C.M. (1983) Instructional Design Theories and Models: An Overview of Their Current Status. Erlbaum, Hillsdale.

[15] Dewiyani, L., et al. (2014) Pengembangan Bahan Ajar Kimia Industri Berbasis CAI (Computer Assisted Instruction). Laporan Akhir, Universitas Muhammadiyah Jakarta, Jakarta. 